\title{
Controlled trial of methotrexate versus 10-deazaaminopterin in the treatment of rheumatoid arthritis
}

Department of Medicine, Division of Clinical Immunology and Rheumatology, The University of Alabama at Birmingham, Birmingham, Alabama, USA

G S Alarcón

W J Koopman

Department of Nutrition Sciences, The University of Alabama at Birmingham, Birmingham, Alabama, USA

C L Krumdieck

Birmingham Veterans Administration Medical Center, Birmingham, Alabama, USA

W J Koopman

Department of Biochemistry,

The University of South Alabama,

Mobile,

Alabama,

USA

M Gopal Nair

Department of Medicine, Rheumatology Unit, Cayetano Heredia Cniversity Hospital,
Unetano Lima,

Peru

G S Alarcón

O Castañeda

M Ferrándiz

Correspondence to: Dr Graciela S Alarcón, 615 MEB-UAB Station, 1813 6th Avenue South, Birmingham, AL 35294 ,

USA.

Accepted for publication 20 September 1991

Graciela S Alarcón, Oswaldo Castañeda, M Gopal Nair, Manuel Ferrándiz, William J Koopman, Carlos L Krumdieck

\begin{abstract}
A 15 week double blind controlled trial of methotrexate and 10-deazaaminopterin for the treatment of rheumatoid arthritis (RA) was performed in 26 patients. Significant improvement in all measured clinical parameters was observed in the two patient groups. The drugs were well tolerated; only one patient (10deazaaminopterin) withdrew from the study because of side effects. It is concluded that, in the context of this relatively short clinical trial, 10-deazaaminopterin is at least as beneficial as methotrexate in the treatment of RA.
\end{abstract}

Aminopterin, a folic acid antagonist, was first used in the treatment of rheumatoid arthritis (RA) in $1951 .{ }^{1}$ Numerous studies have since been published using methotrexate, another folic acid antagonist, in the treatment of this disease, ${ }^{2-5}$ and its use has increased dramatically over the last few years. Compared with other so called disease modifying antirheumatic drugs (DMARDs), methotrexate shows a more rapid response and is more likely to be used for a longer time in a given patient, with toxicity remaining the major factor limiting its use. ${ }^{4}$ The mechanism of action of methotrexate in RA is unknown, but some evidence indicates that it exerts immunomodulatory effects, including the inhibition of lymphocyte proliferation and autoantibody production, ${ }^{6-8}$ whereas other studies indicate that methotrexate exerts antiinflammatory effects including diminished leukotriene $B_{4}$ production and impairment of neutrophil function. ${ }^{9-11}$ As it is likely that these and other effects of methotrexate relate to its ability to inhibit folate dependent pathways, as proposed by a number of workers, ${ }^{12-14}$ we postulated that other antifolates might be equally beneficial and potentially less toxic than methotrexate, thus allowing a given patient to continue receiving an effective drug while experiencing no or limited toxicity. To test this hypothesis, we treated patients with RA with one such compound, 10-deazaaminopterin, previously used experimentally in cancer chemotherapy, ${ }^{15} 16$ and compared its efficacy and safety with methotrexate.

\section{Patients and methods}

PATIENTS

Patients with RA as defined by the revised 1987 American Rheumatism Association classification criteria and followed up at the Cayetano Heredia University Hospital in Lima, Peru were eligible for this trial. Entry criteria for the study included disease of at least six months duration, onset after 16 years of age, and evidence of active disease as determined by three or more swollen joints, six or more tender joints, and morning stiffness of more than 45 minutes duration. Patients also had to be receiving a stable dose of a non-steroidal antiinflammatory drug (NSAID), no more than 10 mg prednisone or equivalent a day, and no DMARD for the two months preceding the trial. Patients with comorbidities, those who had received methotrexate previously, or those not using contraception, if of reproductive potential, were excluded.

\section{STUDY DESIGN}

This was a double blind clinical trial of 15 weeks' duration and was conducted at the Cayetano Heredia University Hospital. The trial was approved by the institution's human use committee and all patients gave written informed consent. Patients were randomised to receive either 10-deazaaminopterin or methotrexate in identical capsules prepared for the study. Codes for all patients were kept in Birmingham (Alabama, USA) and in Lima.

\section{DRUGS}

For this study, 10-deazaaminopterin was synthesised using the approach described previously. ${ }^{17}$ The compound was encapsulated by a local pharmaceutical company (Alabama Pharmaceuticals, Birmingham, AL, USA), and each capsule contained $2.5 \mathrm{mg}( \pm 10 \%)$ of 10 deazaaminopterin. Methotrexate was encapsulated in the same manner as 10-deazaaminopterin. Treatment with methotrexate or 10-deazaaminopterin was started at $7.5 \mathrm{mg} /$ week and the dose increased in $2.5 \mathrm{mg}$ increments at the discretion of the binded investigator. All patients received $1 \mathrm{mg}$ folic acid a day for the seven days preceding the trial.

\section{CLINICAL ASSESSMENT}

A baseline (visit 0 ) evaluation including a complete history, physical examination, and determination of eligibility criteria was performed. Hand and wrist radiographs were also obtained at this time and were read blindly by one of the authors (GSA) using the modified method of Sharp. ${ }^{18}$ Thereafter visits took place every three weeks for a total of 15 weeks (visits one to six). The following clinical variables were 
assessed during each of these visits: joint counts for pain or tenderness in 60 diarthrodial joints measured on a scale of 0 (no pain or tenderness) to 3 (maximum pain or tenderness); joint counts for swelling in the same joints, with the exception of hips, using the same scale; duration of morning stiffness to the nearest five minutes, grip strength as measured with a mercury sphygnomanometer inflated to $20 \mathrm{~mm}$ and averaged after three readings; patient and doctor assessment of disease activity measured on a scale of $0-4$ with 0 being asymptomatic and 4 very severe; adverse reactions and their possible relation to the study drugs; and compliance with drug regimen. Degree of pain on a scale of 0 (no pain) to 3 (very severe pain) and functional level on a scale of 0 to 20 , with 0 being no functional limitations and 20 very severe limitations, were ascertained at visits one and six. Significant clinical improvement was defined as a reduction of $50 \%$ or more in either the joint count for swelling or for pain and tenderness, or both.

Laboratory parameters including complete blood cell count with differential and platelet count, creatinine, alkaline phosphatase, and serum aspartate aminotransferase were determined every three weeks. Serum rheumatoid factor, Westergren erythrocyte sedimentation rate, and chest, hand, and wrists radiographs were obtained at baseline. Serum samples were obtained and frozen at visits one and six and shipped to Birmingham for further studies.

\section{STATISTICAL ANALYSIS}

The results for visits zero, three, and six were compared within study groups and their difference (or gain scores) between study groups. Student's $t$ test was used to compare continuous

Table 1 Selected baseline clinical features of patients with rheumatoid arthritis taking part in this trial. Results are mean (SD)

\begin{tabular}{lcc}
\hline Clinical feature & $\begin{array}{l}10-\text { Deazaaminopterin } \\
(n=13)\end{array}$ & $\begin{array}{c}\text { Methotrexate } \\
(n=13)\end{array}$ \\
\hline Duration of disease (years) & $5 \cdot 4(4 \cdot 6)$ & $4 \cdot 1(3 \cdot 2)$ \\
Joint count for pain/tenderness & $48 \cdot 2(29 \cdot 9)$ & $35 \cdot 9(16 \cdot 8)$ \\
Joint count for swelling & $40 \cdot 7(30 \cdot 9)$ & $31 \cdot 4(12 \cdot 4)$ \\
Duration of morning stiffness (hours) & $1 \cdot 7(1 \cdot 7)$ & $1 \cdot 3(0 \cdot 8)$ \\
Grip strength (mmHg) & $123 \cdot 6(53 \cdot 7)$ & $122 \cdot 6(35 \cdot 2)$ \\
Overall patient assessment (0-4) & $2 \cdot 9(0 \cdot 5)$ & $3 \cdot 2(0 \cdot 7)$ \\
Overall doctor assessment (0-4) & $2 \cdot 9(0 \cdot 4)$ & $3 \cdot 0(0 \cdot 4)$ \\
Degree of pain (1-3) & $1 \cdot 9(0 \cdot 3)$ & $2 \cdot 3(0 \cdot 6)$ \\
Functional level (0-20) & $7 \cdot 4(1 \cdot 9)$ & $6 \cdot 9(1 \cdot 9)$ \\
Rheumatoid factor positivity (latex fixation titre & & 77 \\
₹l/320) (\%) & 92 & 31 \\
Prednisone use (\%) & 8 & \\
\hline
\end{tabular}

None of the comparisons are significant ( $p>0.05)$. data, and the $\chi^{2}$ distribution, with Yates's correction as appropriate, for dichotomous data. No adjustment for baseline variables was needed. Two tailed tests were used in all instances. A p value of $\leqslant 0.05$ was chosen as the level of significance.

\section{Results}

Twenty six patients entered this trial with 13 being assigned to each group; 23 patients completed the trial. One patient in the 10deazaaminopterin group withdrew from the study because of adverse side effects, whereas the other two patients, one in the methotrexate and one in the 10-deazaaminopterin group, were lost to follow up. Patients were predominantly women $(96 \%)$, all mestizo (i.e. with Hispanic and Andean indian ethnic backgrounds), and had a mean (SD) age of 45.5 $(11 \cdot 5)$ years. These demographic features were similar for the two study groups. All patients were receiving a stable dose of an NSAID and a few were receiving corticosteroids by mouth at a dose not greater than $10 \mathrm{mg}$ prednisone (or equivalent). Table 1 shows these and additional baseline clinical data for the two study groups. The variables examined, including duration of disease, joint count for pain or tenderness and swelling, duration of morning stiffness, grip strength, overall doctor and patient assessment, degree of pain, and functional level, were comparable at baseline for the two study groups. Baseline laboratory parameters and radiographic scores (data not shown) were also similar for the two study groups. Over the duration of the study, the mean weekly 10-deazaaminopterin and methotrexate doses were 7.7 and $8.9 \mathrm{mg}$ respectively.

Significant clinical improvement at visit six (as defined under Methods) occurred in 10 of the 12 methotrexate treated patients and in nine of the 11 10-deazaaminopterin treated patients ( 83 and $82 \%$ respectively). At visits three and six, patients in the two treatment groups had had a significant improvement in the joint counts for pain or tenderness and for swelling, duration of morning stiffness, degree of pain, and grip strength (table 2). When the mean of the gain scores between visits three and zero were compared, no significant difference between the two treatment groups was found (table 3), except for overall patient assessment which was better at visit three in the methotrexate treated patients, and functional level

Table 2 Baseline and follow up data for studied patients with rheumatoid arthritis treated with methotrexate and 10-deazaaminopterin. Results are mean $(S D)$

\begin{tabular}{|c|c|c|c|c|c|c|c|c|c|c|}
\hline \multirow[t]{3}{*}{ Clinical feature } & \multicolumn{5}{|c|}{ 10-Deazaaminopterin ${ }^{*}$} & \multicolumn{5}{|l|}{ Methotrexate ${ }^{*}$} \\
\hline & \multirow{2}{*}{$\begin{array}{l}V_{0} \\
(n=13)\end{array}$} & \multirow{2}{*}{$\begin{array}{l}V_{3} \\
(n=13)\end{array}$} & \multirow{2}{*}{$\begin{array}{l}V_{6} \\
(n=11)\end{array}$} & \multicolumn{2}{|c|}{ p Value } & \multirow{2}{*}{$\begin{array}{l}V_{0} \\
(n=13)\end{array}$} & \multirow{2}{*}{$\begin{array}{l}V_{3} \\
(n=13)\end{array}$} & \multirow{2}{*}{$\begin{array}{l}V_{6} \\
(n=12)\end{array}$} & \multicolumn{2}{|c|}{ p Value } \\
\hline & & & & $V_{5}-V_{0}$ & $V_{6}-V_{0}$ & & & & $V_{5}-V_{0}$ & $V_{\sigma}-V_{\theta}$ \\
\hline $\begin{array}{l}\text { Joint count for pain/tenderness } \\
\text { Joint count for swelling } \\
\text { Duration of morning stiffness (hours) } \\
\text { Grip strength (mmHg) } \\
\text { Overall patient assessment (0-4) } \\
\text { Overall doctor assessment (0-4) } \\
\text { Degree of pain (1-3) } \\
\text { Functional level }(0-20)\end{array}$ & $\begin{array}{r}48.2(29.9) \\
40.7(30.9) \\
1.7(1.7) \\
123.6(53.7) \\
2.9(0.5) \\
2.9(0.4) \\
1.9(0.3) \\
7.4(1.9)\end{array}$ & $\begin{array}{c}31 \cdot 1(23 \cdot 7) \\
25 \cdot 8(18 \cdot 2) \\
0 \cdot 6(0 \cdot 5) \\
136 \cdot 3(53 \cdot 7) \\
2 \cdot 5(0 \cdot 7) \\
2 \cdot 4(0 \cdot 5) \\
=-\end{array}$ & $\begin{array}{r}17 \cdot 4(18 \cdot 8) \\
19 \cdot 2(17 \cdot 7) \\
0.5(0 \cdot 6) \\
154 \cdot 1(65 \cdot 4) \\
2.0(0 \cdot 6) \\
2 \cdot 2(0 \cdot 6) \\
1.2(0 \cdot 6) \\
3.5(2 \cdot 7)\end{array}$ & $\begin{array}{l}0.004 \\
0.021 \\
0.023 \\
0.038 \\
0.017 \\
0.003 \\
-\end{array}$ & $\begin{array}{l}0.008 \\
0.015 \\
0.014 \\
0.010 \\
0.002 \\
0.004 \\
0.001 \\
0.001\end{array}$ & $\begin{array}{r}35.9(16.8) \\
31.4(12.5) \\
1.3(0.8) \\
122.6(35 \cdot 2) \\
3.2(0 \cdot 7) \\
3.0(0.4) \\
2.3(0.6) \\
6.9(1.9)\end{array}$ & $\begin{aligned} & 18 \cdot 7(16 \cdot 6) \\
& 21 \cdot 4(13 \cdot 5) \\
& 0 \cdot 3(0 \cdot 6) \\
& 143 \cdot 6(35 \cdot 6) \\
& 2 \cdot 2(0 \cdot 6) \\
& 2 \cdot 2(0 \cdot 4) \\
&= \\
&=\end{aligned}$ & $\begin{array}{r}10.6(14.8) \\
13.5(13.5) \\
0.4(0.9) \\
158 \cdot 2(48 \cdot 5) \\
2 \cdot 1(0.9) \\
2 \cdot 1(0.8) \\
1.3(1.0) \\
3.6(2 \cdot 4)\end{array}$ & $\begin{array}{l}0.002 \\
0.020 \\
0.001 \\
0.024 \\
0.001 \\
0.001 \\
-\end{array}$ & $\begin{array}{l}0.001 \\
0.006 \\
0.001 \\
0.025 \\
0.001 \\
0.001 \\
0.002 \\
0.001\end{array}$ \\
\hline
\end{tabular}


Table 3 Comparison between mean gain scores at visit 3 and at trial completion for methotrexate and 10-deazaaminopterin treated patients with rheumatoid arthritis. Assessed in all patients between visits three and zero and between visits six and visit three in 11 10-deazaaminopterin and 12 methotrexate treated patients. Results are mean (SD)

\begin{tabular}{|c|c|c|c|c|}
\hline \multirow[t]{2}{*}{ Clinical feature } & \multicolumn{2}{|c|}{ 10-Deazaaminopterin } & \multicolumn{2}{|l|}{ Methotrexate } \\
\hline & $\begin{array}{l}V_{3}-V_{0} \\
(n=13)\end{array}$ & $\begin{array}{l}V_{6}-V_{3} \\
(n=11)\end{array}$ & $\begin{array}{l}V_{3}-V_{0} \\
(n=13)\end{array}$ & $\begin{array}{l}V_{6}-V_{3} \\
(n=13)\end{array}$ \\
\hline $\begin{array}{l}\text { Joint count for pain/tenderness } \\
\text { Joint count for swelling } \\
\text { Duration of morning stiffness (hours) } \\
\text { Grip strength (mmHg) } \\
\text { Overall patient assessment }(0-4) \\
\text { Overall doctor assessment }(0-4) \\
\text { Degree of pain }(1-3) \\
\text { Functional level }(0-20)\end{array}$ & $\begin{array}{r}-17 \cdot 1(19 \cdot 6) \\
-14 \cdot 9(20 \cdot 2) \\
-1 \cdot 1(1 \cdot 5) \\
12 \cdot 7(18 \cdot 7) \\
-0 \cdot 4(0 \cdot 5)^{*} \\
-0 \cdot 5(0 \cdot 5) \\
-0 \\
-3\end{array}$ & $\begin{array}{c}-17 \cdot 2(21 \cdot 0) \\
-10 \cdot 0(15 \cdot 1) \\
-0 \cdot 3(0 \cdot 4) \\
2 \cdot 4(32 \cdot 6) \\
-0 \cdot 5(0 \cdot 5) \\
-0 \cdot 2(0 \cdot 6) \\
\end{array}$ & $\begin{array}{r}-17 \cdot 2(16 \cdot 5) \\
-10 \cdot 0(12 \cdot 7) \\
-1 \cdot 0(0 \cdot 8) \\
21 \cdot 0(30 \cdot 3) \\
-1 \cdot 0(0 \cdot 8)^{*} \\
-0 \cdot 8(0 \cdot 6) \\
-1 \\
-3\end{array}$ & $\begin{array}{c}-9 \cdot 5(11 \cdot 2) \\
-8 \cdot 1(12 \cdot 7) \\
0.1(0 \cdot 7) \\
10 \cdot 5(29 \cdot 5) \\
0 \cdot 1(0 \cdot 7) \\
-0 \cdot 1(0 \cdot 7) \\
\end{array}$ \\
\hline
\end{tabular}

${ }^{*}$ Significant at $\mathrm{p}>0.05$.

which was better at visit six in the 10deazaaminopterin treated pat'ents. When all the patients were included in these analyses (intent to treat analysis, data not shown), the results remained essentially unchanged.

Adverse drug reactions occurred in three patients, two receiving 10-deazaaminopterin and one receiving methotrexate. One patient receiving 10-deazaaminopterin developed a transient rash and another moderate nausea, vomiting, and abdominal pain, which resulted in discontinuation of the drug, whereas one patient in the methotrexate group developed transient headaches and dizziness.

Laboratory abnormalities were detected in the two treatment groups, but were not significant enough to discontinue the drug in any patient. Out of 14 possible determinations for each patient for serum aspartate aminotransferase $^{7}$ and alkaline phosphatase, ${ }^{7}$ they were increased 3.4 times in the 10deazaaminopterin and 2.8 times in the methotrexate treated patients $(p>0.05)$. It should be noted that most of these abnormalities were minimal. Isolated increases twice or more the normal value for either serum aspartate aminotransferase or alkaline phosphatase occurred in only two 10-deazaaminopterin and four methotrexate treated patients. There were no significant changes in the white blood cell and platelet counts for patients in the two study groups. Serum creatinine increased only once in one methotrexate treated patient and in none of the 10-deazaaminopterin treated patients.

\section{Discussion}

Over the last decade methotrexate has become an important drug within the relatively limitec range available to the practising rheumatologist. Although the response to this drug is prompt and predictable, toxicity remains an important problem. $^{2-5,} 19$ Methotrexate is a folic acid antagonist capable of inhibiting a number of folate dependent pathways, particularly after undergoing polyglutamylation within the cell. The mechanism of action of methotrexate in RA remains largely speculative and no definitive relation between its antifolate activity and its antirheumatic effects has been definitely established. ${ }^{12-14}$ Indeed, the toxicity of methotrexate is reduced in folate supplemented patients with $\mathrm{RA}^{20}$; however, no decreased efficacy was observed in these patients, suggest- ing that the mechanisms(s) underlying efficacy and toxicity can be partially dissociated. Our data $^{12-14}$ indicate the therapeutic efficacy of another antifolate drug, 10-deazaaminopterin, in RA. Taken in conjunction with these earlier data, ${ }^{12-14}$ our results support the suggestion that the antifolate activity of 10-deazaaminopterin and methotrexate is central to the antirheumatic activity of these drugs.

The present trial shows the usefulness of 10deazaaminopterin, a classical antifolate which can undergo polyglutamylation, in the treatment of RA compared with methotrexate. It might be argued that a placebo group, rather than methotrexate would have enhanced the strength of this trial, but comparison with another antifolate which had already proved to be efficacious in the treatment of $\mathrm{RA}^{2-5}$ was considered to be a reasonable alternative. In addition to an improvement in all clinical efficacy parameters at the completion of the trial in the two treatment groups, a similar proportion of patients experienced an improvement as defined by a reduction of $\geqslant 50 \%$ in the joint count for swelling or pain and tenderness, or both.

Baseline demographic and clinical features were similar in all patients studied, with 23 of the 26 patients completing the trial. 10Deazaaminopterin appeared to be at least as beneficial as methotrexate in this trial. Although four of the eight outcome measurements favoured 10-deazaaminopterin over methotrexate, these differences did not reach statistical significance. It is possible that if we studied a larger number of patients, we might have observed significant differences between the two drugs. The results were similar when all patients (intent to treat analysis) were also included. Whether 10-deazaaminopterin remains beneficial in the treatment of RA for more than a short time remains to be determined. After this trial was completed, patients were given the opportunity to continue receiving these drugs (blinded) for one year. At the present time, this phase of the study is being completed; though no definite results are available, we have not observed any serious toxic event, or a lack of efficacy in these patients.

Few side effects were observed in either group. We assumed, before the trial was started, that the population from which the study patients were drawn was likely to be marginally deficient in folate (there is a less than optimal 
nutritional status in this population $)^{21}$ and thus all patients were supplemented with folic acid before the trial started. This practice may explain the relatively few and mild adverse reactions observed during the short duration of this trial and, thus, a conclusive statement regarding the toxicity of 10-deazaaminopterin compared with methotrexate cannot be made at this time. Likewise, laboratory parameters including white blood cell and platelet counts, creatinine, alkaline phosphatase, and serum aspartate aminotransferase changed in the two study groups, but only in a few instances was either enzyme increased two or more times the normal value. These changes were comparable for patients in the two study groups.

In summary, our experience with 10deazaaminopterin has been favourable in this limited trial, but determining the long term efficacy and safety of this drug requires further evaluation. These data, taken in conjunction with previously published reports, strongly support the use of antifolates in the treatment of RA. 10-Deazaaminopterin and other antifolate drugs may be reasonable alternatives to methotrexate in the treatment of RA.

We thank Ella Henderson, The University of Alabama at Birmingham and Lucy Spencer, Cayetano Heredia University Hospital for their help during the trial and for manuscript Hospital for their help during the trial and for manuscript preparation. This work was partially supported by NIH grants
ARO 3555, 2 R01-CA 28103 and CA 27101. Methotrexate was a gift of Dr J A R Mead of the National Cane Institute (USA).

1 Gubner R, August S, Ginsberg V. Therapeutic suppression of tissue reactivity. II. Effect of aminopterin in rheumatoid arthritis and psoriasis. Am $\mathcal{F}$ Med Sci 1951; 221: 176-82.

2 Williams H J, Willkens R F, Samuelson C O, Jr, et al. Comparison of low-dose oral pulse methotrexate and placebo in the treatment of rheumatoid arthritis: a controlled clinical trial. Arthritis Rheum 1985; 28: 721-30.

3 Weinblatt M E, Coblyn J S, Fox D A, et al. Efficacy of lowdose methotrexate in rheumatoid arthritis. $N$ Engl $\mathcal{F}$ Med 1985; 312: 818-22

4 Alarcón G S, Tracy I C, Blacburn W D Jr. Methotrexate in rheumatoid arthritis: toxic effects as the major factor in limiting long-term treatment. Arthritis Rheum 1989; 32: 671-6.
5 Tugwell $\mathrm{P}$, Bennett $\mathrm{K}$, Gent $\mathrm{M}$. Methotrexate in rheumatoid arthritis: indications, contraindications, efficacy and safety. Ann Intern Med 1988; 107: 358-66.

6 Olsen N J, Callahan L F, Pincus T. Immunologic studies of rheumatoid arthritis patients treated with methotrexate. Arthritis Rheum 1987; 30: 481-8.

7 Alarcón G S, Schrohenloher R E, Bartolucci A A, Ward J R, Williams H J, Koopman W J. Suppresion of rheumatoid factor production by methotrexate in patients with rheuma-
toid arthritis: evidence for differential influences of therapy and clinical status on IgM and IgA rheumatoid factor expression. Arthritis Rheum 1990; 33: 1156-61.

8 Hine R J, Everson M P, Hardin J M, et al. Methotrexate therapy in rheumatoid arthritis patients diminishes lectininduced mononuclear cell proliferation. Rheumatol Int 1990; 10: 165-9.

9 Bahremand M, Schumacher H R Jr, Korchak H. Effects of methotrexate (MTX) on neutrophil (PMN) enzyme release. Arthritis Rheum 1990; 33: S38.

10 Eberle M, Marchetta P, Levin R, Cronstein B. A novel antiinflammatory action of methotrexate (MTX): MTX increases adenosine release from connective cells and thereby inhibits neutrophil (PMN) function. Arthritis Rheum 1990; 33: S39.

11 Sperling R I, Larkin J K, Coblyn J, Benicaso A I, Austen K F, Weinblatt M E. Inhibition of leukotriene B4 synthesis in neutrophils of patients with rheumatoid arthritis by a single dose of methotrexate. Arthritis Rheum 1990; 33: 1149-55.

12 Tishler M, Caspi D, Fishel B, Yaron M. The effects of levcovorum (folinic acid) on methotrexate therapy in rheumatoid arthritis patients. Arthritis Rheum 1988; 31: ro6-8.

13 Tishler M, Caspi D, Rosenbach T O, et al. Methotrexate in the treatment of rheumatoid arthritis: a prospective study in Israeli patients with immunogenetic correlations. Ann Rheum Dis 1988; 47: 654-9.

14 Hanrahan P S, Scrivens G A, Russell A S. Prospective long term follow up of methotrexate therapy in rheumatoid arthritis: toxicity, efficacy and radiological progression. $\mathrm{Br}$ arthritis: toxicity, efficacy and

15 Currie V E, Warrell R P, Arlin Z, et al. Phase I trial. 10-Deaza-aminopterin in patients with advanced cancer. Cancer Treatment Rep 1983; 67: 149-54.

16 Cheng E W, Currie V E, Yagoda A. Phase II trial of 10-deazaaminopterin in patients with advanced colorectal cancer. Am 7 Clin Oncol 1983; 6: 469-71.

17 Nair M G. Folate analogues, 24: synthesis of the antitumour agents 10-deazaaminopterin. F Org Chem 1985; 50: $1879-84$.

18 Sharp J T, Young D Y, Blumh G B, et al. How many joints in the hands and wrists should be included in a score of radiologic abnormalities used to assess rheumatoid arthritis? Arthritis Rheum 1985; 28: 1326-35.

19 Gispen J G, Alarcón G S, Johnson J J, Acton R T, Barger B O, Koopman W J. Toxicity to methotrexate in rheumatoid arthritis. F Rheumatol 1987; 14: 74-9.

20 Morgan S L, Baggott J E, Vaughan W H, et al. The effect of folic acid supplementation on the toxicity of low-dose methotrexate in patients with rheumatoid arthritis. Arthritis Rheum 1990; 33: 9-18

21 Llosa L, Seraylan S, Alvarez J. Anemia por deficiencia de hierro y folato en mujeres embarazadas en Lima, Perú (Iron and folic acid deficiency in pregnant women in Lima, Peru). Diagnóstico 1988; 21: 133-9. 